\title{
Morphological Characteristics and Body Composition of the Winners of the Soccer Cup of Bosnia and Herzegovina and Kosovo
}

\author{
Jovan Gardasevic', Dusko Bjelica', Ivan Vasiljevic ${ }^{1}$, Marin Corluka² ${ }^{1}$ Fitim Arifi ${ }^{3}$ and Sami Sermaxhaj \\ 'University of Montenegro, Faculty for Sport and Physical Education, Niksic, Montenegro, ${ }^{2}$ University of Mostar, Faculty of Mathematics and Science \\ Education, Mostar, Bosnia and Herzegovina, ${ }^{3}$ University of Tetovo, Faculty for Sport and Physical Education, Tetovo, North Macedonia, 4 Universi \\ College, Department of Physical Culture, Sport and Recreation, Pristina, Kosovo
}

\section{Abstract}

This research aimed to determine the differences among the top soccer players of a club in Bosnia and Herzegovina, FC Siroki Brijeg, and the top soccer players of a club in Kosovo, FC Besa Peje, the winners of the Soccer Cup in their countries, in the morphological characteristics and body composition. A sample of 40 subjects was divided into two sub-samples. The first sub-sample consisted of 22 players FC Siroki Brijeg, the average age of 24.00 \pm 6.22 , the winner of the Cup of Bosnia and Herzegovina in the season 2016/17, while the other sub-sample consisted of 18 players of FC Besa Peje of the average age of 21.83 \pm 3.17 , the winner of the Cup of Kosovo in the 2016/17 season. Soccer players were tested immediately after the end of the 2016/17 competition season. Morphological characteristics were evaluated using a battery of seven variables: body height, body weight, waist circumference, triceps skinfold, biceps skinfold, skinfold of the back, and abdominal skinfold. The body composition was evaluated using a battery of three variables: body mass index, fat percentage, and muscle mass. The standard central and dispersion parameters of all variables were calculated. The significance of the differences between the players of the top two soccer clubs in the morphological characteristics and variables for assessing body composition was determined using a t-test for independent samples. The t-test results showed a statistically significant difference only in two variables waist circumference and triceps skinfold.
\end{abstract}

Keywords: soccer, morphological characteristics, body composition

\section{Introduction}

A soccer game is said to be the most important secondary thing in the world; it gathers huge masses at stadiums and in front of TVs (Gardasevic, Bjelica, \& Vasiljevic, 2019). It is a highly dynamic and fast team game that, with its richness of movement, belongs to the category of polystructural sports games (Gardasevic, Bjelica, \& Corluka, 2018; Bjelica, Popovic, Gardasevic, \& Krivokapic, 2016). Soccer is a sport that is characterized by numerous and various complex and dynamic kinesiological activities, which are then characterized by either cyclical (Sermaxhaj, Popovic, Bjelica, Gardasevic, \& Arifi, 2017; Gardasevic, Bjelica, \& Vasiljevic, 2017) or acyclical movement (Gardasevic, Bjelica, \& Vasiljevic, 2016; Gardasevic, Bjelica, Milasinovic \& Vasiljevic, 2016; Gardasevic, Popovic, \& Bjelica, 2016). In sport, top scores can be achieved only under conditions of well-programmed training processes (Gardasevic, Akpinar, Popovic, \& Bjelica, 2019; Gardasevic \& Bjelica, 2019; Bjelica, Popovic, Tanase, \& Gardasevic, 2017; Bojanic, Petkovic, Gardasevic, Muratovic, \& Vasiljevic, 2015). Various studies are to be done to establish certain principles and norms for the

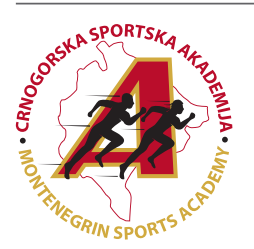

Correspondence: 
transformational processes of the anthropological characteristics essential for soccer (Bjelica \& Gardasevic, 2018; Bjelica, Popovic, \& Gardasevic, 2016a; Bjelica, Popovic, \& Gardasevic, 2016b); with morphological characteristics and body composition among them as expected (Vasiljevic, Bjelica, \& Gardasevic, 2018; Corluka, Bjelica, \& Gardasevic, 2018; Vasiljevic, Bjelica, Popovic, \& Gardasevic, 2015; Gardasevic, Vasiljevic, Bjelica, \& Popovic, 2015). Findings regarding morphological characteristics and body composition are of crucial importance for complex sports such as soccer (Milasinovic, Gardasevic, \& Bjelica, 2017; Gardasevic, Rasidagic, Krivokapic, Corluka, \& Bjelica, 2017). Research on morphological characteristics and body composition among athletes of different sports indicates that such athletes have their own specific characteristics (Gardasevic, 2019; Gardasevic, 2018; Gardasevic, Masanovic, \& Arifi, 2018; Masanovic, Gardasevic, \& Arifi, 2018a; Masanovic, Gardasevic, \& Arifi, 2018b; Arifi, Sermaxhaj, Gardasevic, Alaj, \& Metaj, 2018; Arifi, Gardasevic, \& Masanovic, 2018; Arifi et al., 2017).

Today, soccer is undoubtedly the number one sport in the world in popularity (Gardasevic, Georgiev, \& Bjelica, 2012), and the same applies to Bosnia and Herzegovina and Kosovo (Bjelica, Gardasevic, Vasiljevic, Arifi, \& Sermaxhaj, 2019; Gardasevic, Bjelica, Vasiljevic, Arifi, \& Sermaxhaj, 2019).

In the 2016/17 competitive season, FC Siroki Brijeg was the winner of the Cup of Bosnia and Herzegovina, and FC Besa Peje was the winner of the Cup of Kosovo. This research aimed to analyse the differences in some morphological characteristics and body composition among top soccer players of FC Siroki Brijeg and FC Besa Peje.

\section{Methods}

A sample of the subjects consists of a total of 40 top-level soccer players, divided into two sub-samples. The first one consists of 22 players of FC Siroki Brijeg, the average age of $24.00 \pm 6.22$, the winner of the Cup of Bosnia and Herzegovina, and the second one that consists of 18 players of FC Besa Peje of the average age of $21.83 \pm 3.17$, the winner of the Cup of Kosovo in the season 2016/17.

Morphological research has been carried out with respect to the basic rules and principles related to the selection of measuring instruments and measurement techniques standardized in accordance with the International Biological Program guidelines. For this study, seven morphological measures have been taken (body height, body weight, waist circumference, triceps skinfold, biceps skinfold, skinfold of the back, and abdominal skinfold) and three body composition assessment variables (body mass index, fat percentage, and muscle mass). An anthropometer, calliper, and measuring tape were used for morphological measurements. To evaluate the body composition, Tanita body fat scale - model BC-418MA, was used.

Differences in morphological characteristics and the composition of the body of the players of these two clubs were determined by using a discriminatory parametric procedure with t-test for small independent samples, with statistical significance of $\mathrm{p}<0.05$.

\section{Results}

Based on the obtained values of t-test results, it can be noted that there are statistically significant differences in two variables at $\mathrm{p}<0.05$. It is two morphological measures waist circumference and triceps skinfold. It can be stated that the soccer players of FC Siroki Brijeg have statistically significantly higher waist circumference and smaller triceps skinfold than the players of FC Besa Peje do (Figure 1). In all other variables, the differences are negligible and not statistically significant.
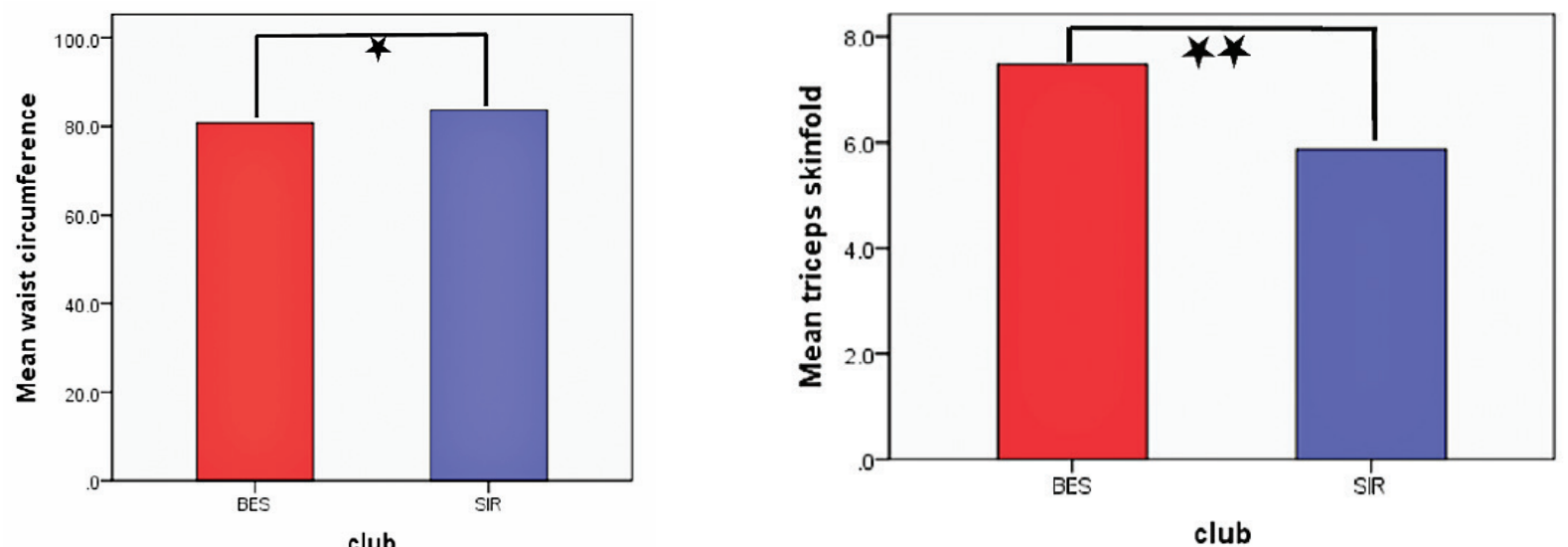

Figure 1. Statistically significant differences between soccer players FC Siroki Brijeg (SIR) and FC Besa Peje (BES) in two variables $\left({ }^{*} p<.05 ;{ }^{* *} p<.01\right)$

\section{Discussion}

It can be observed that the players of both clubs are of the approximately similar mean values of the variables analysed, which is not surprising because these are the top two clubs in Bosnia and Herzegovina and Kosovo. Gardasevic, Bjelica, and Vasiljevic (2019) found similar results on a sample of soccer players from Montenegro. Very similar anthropometric characteristics of soccer players were obtained, which shows that they have similar characteristics and body composition throughout the region (Gardasevic, Bjelica, Popovic, Vasiljevic, \& Milosevic, 2018; Corluka \& Vasiljevic, 2018). The t-test results showed a statistically significant dif- ference only in two variables: waist circumference and triceps skinfold. For other variables, some values are better for players of FC Siroki Brijeg and some for players of FC Besa Peje, although, insignificantly for statistics, which indicates that these players have very similar body composition and anthropometric parameters. The values obtained in this research can be useful for coaches of these clubs for making a comparison of their players with others and formulate their work in a way that enables a reduction of those parameters that are not beneficial and raising those that are to a higher level. That will surely make their soccer players even better and more successful. Furthermore, both clubs should turn 
to other research studies and check the functional-motoric status, psychological preparation, and tactical training of

\section{Acknowledgements}

There are no acknowledgements.

\section{Conflict of Interest}

The authors declare that there are no conflicts of interest.

Received: 11 November 2019 | Accepted: 05 January 2020 | Published: 01 February 2020

\section{References}

Arifi, F., Bjelica, D., Sermaxhaj, S., Gardasevic, J., Kezunovic, M., \& Popovic S. (2017). Stature and its estimation utilizing arm span measurements in Kosovan adults: National survey. International Journal of Morphology, 35(3), 1161-1167.

Arifi, F., Sermaxhaj, S., Gardasevic, J., Alaj, I., \& Metaj, Z. (2018). Stature and its estimation utilizing arm span measurements of both gender adolescents from southern region in Kosovo. Sport Mont, 16(2), 51-54. doi: $10.26773 /$ smj.180609

Arifi, F., Gardasevic, J., \& Masanovic, B. (2018). Relationship between foot length measurements and body height: A prospective regional study among adolescents in central region of Kosovo. Sport Mont, 16(3), 75 79. doi: $10.26773 /$ smj. 181013

Bjelica, D., Popovic, S., \& Gardasevic, J. (2016a). Dependence of basketball repulsion on the pressure within this sport. Journal of Physical Education and Sport, 16(1), 125-131. doi:10.7752/jpes.2016.01021

Bjelica, D., Popovic, S., \& Gardasevic, J. (2016b). Pressure dependence of handball repulsion within this sport. Journal of Physical Education and Sport, 16(Suppl 2), 1078-1083. doi:10.7752/jpes.2016.s2172

Bjelica, D., Popovic, S., Gardasevic, J., \& Krivokapic, D. (2016). Dependence of Football Repulsion on the Pressure within This Sport. Journal of Physical Education and Sport, 16(2), 452-458. doi:10.7752/jpes.2016.02069

Bjelica, D., Popovic, S., Tanase, G.D., \& Gardasevic, J. (2017). Dependence of female ball in handball repulsion on the pressure within this sport. Acto Kinesiologica, 11(Supp. 1), 67-72

Bjelica, D. \& Gardašević, J. (2018). Volleyball elastic properties depending on ball pressure. Sport Science, 11(1), 45-51.

Bjelica, D., Gardasevic, J., Vasiljevic, I., Arifi, F., \& Sermaxhaj, S. (2019). Anthropometric measures and body composition of soccer players of Montenegro and Montenegro. Journal of Anthropology of Sport and Physical Education, 3(2), 29-34. doi: 10.26773/jaspe.190406

Corluka, M., \& Vasiljevic, I. (2018). Differences in the Anthropometric characteristics and body composition of soccer players in Montenegro. Journal of Anthropology of Sport and Physical Education, 2(1), 3-7. doi: 10.26773/jaspe.180101

Corluka, M., Bjelica, D., \& Gardasevic, J. (2018). Sport schools vs trends to obesity: an analysis among 5 year olds in the Makarska (Croatia). Acto Kinesiologica, 12(1), 111-115.

Gardasevic, J., Georgiev, G., \& Bjelica, D. (2012). Qualitative changes of basic motor abilities after completing a six-week training programme. Acto Kinesiologica, 6(1), 70-74.

Gardasevic, J., Vasiljevic, I., Bjelica, D., \& Popovic, S. (2015). Analysis of nutrition of boys and girls, adolescents from Montenegro. Journal of Physical Education and Sport, 15(4), 702-704. doi:10.7752/jpes.2015.04107

Gardasevic, J., Bjelica, D., \& Vasiljevic, I. (2016). Six-Week Preparation Period and its Effects on Transformation Movement Speed with Soccer Players under 16. Sport Mont, 14(1), 13-16.

Gardasevic, J., Bjelica, D., Milasinovic, R. \& Vasiljevic, I. (2016). The Effects of the Training in the Preparation Period on the Repetitive Strength Transformation with Cadet Level Soccer Players. Sport Mont, 14(2), 31-33.

Gardasevic, J., Popovic, S. \& Bjelica, D. (2016). After preparation period ball shooting accuracy at players U15. In Abstract Book of the 8th Conference for Youth Sport (88), Ljubljana: University of Ljubljana, Faculty of Sport. their players and analyse whether there is room for their improvement.

Gardasevic, J., Rasidagic, F., Krivokapic, D., Corluka, M., \& Bjelica, D. (2017). Stature and Its Estimation Utilizing Arm Span Measurements in Male Adolescents from Federation of Bosnia and Herzegovina Entity in Bosnia and Herzegovina. Montenegrin Journal of Sports Science and Medicine, 6(1), 37-44. udc: 572.512-053.8(497.6)

Gardasevic, J., Bjelica, D., \& Vasiljevic, I. (2017). The Strength of Kicking the Ball after Preparation Period with U15 Soccer Players. Sport Mont, 15(2), 39-42.

Gardasevic, J., Bjelica, D., Popovic, S., Vasiljevic, I., \& Milosevic, Z. (2018). Differences in the Anthropometric characteristics and body composition of soccer players FC Buducnost and FC Mladost in Montenegro. Journal of Anthropology of Sport and Physical Education, 2(1), 51-55. doi: 10.26773/jaspe.180109

Gardasevic, J., Bjelica, D., \& Corluka, M. (2018). The impact of the preparation period on endurance at football players U16. Sport Mont, 16(1), 21-24. doi: $10.26773 /$ smj.180204

Gardasevic, J. (2018). Relationship between sitting height measurements and standing height: a prospective regional study among adolescents in eastern region of Kosovo. Sport Mont, 16(2), 15-19. doi: 10.26773/ smj. 180603

Gardasevic, J., Masanovic, B., \& Arifi, F. (2018). Relationship between tibia length measurements and standing height: $A$ prospective regional study among adolescents in southern region of Kosovo. Sport Mont, 16(3), 51-55. doi: 10.26773/smj.181009

Gardasevic, J., \& Bjelica, D. (2019). Shooting ball accuracy with u16 soccer players after preparation period. Sport Mont, 17(1), 29-32. doi: 10.26773/ smj.190205

Gardasevic, J., Bjelica, D., \& Vasiljevic, I. (2019). Morphological characteristics and body composition of elite soccer players in Montenegro. International Journal of Morphology, 37(1), 284-288.

Gardasevic, J., Akpinar, S., Popovic, S., \&Bjelica, D. (2019). Increased Perceptual and Motor Performance of the Arms of Elite Water Polo Players. Applied Bionics and Biomechanics, 6763470. doi: 10.1155/2019/6763470.

Gardasevic, J. (2019). Standing height and its estimation utilizing tibia length measurements in adolescents from western region in Kosovo. International Journal of Morphology, 37(1), 227-231.

Gardasevic, J., Bjelica, D., Vasiljevic, I., Arifi, F., \& Sermaxhaj, S. (2019). Body composition of elite soccer players from montenegro and kosovo. Sport Mont, 17(3), 27-31. doi: 10.26773/smj.191011

Masanovic, B., Gardasevic, J., \& Arifi, F. (2018a). Relationship between foot length measurements and body height: A prospective regional study among adolescents in eastern region of Kosovo. Sport Mont, 16(1), 9-13. doi: $10.26773 /$ smj. 180202

Masanovic, B., Gardasevic, J., \& Arifi, F. (2018b). Relationship between foot length measurements and standing height: a prospective regional study among adolescents in southern region of Kosovo. Sport Mont 16(2), 27-31. doi: 10.26773/smj.180605

Milasinovic, R., Gardasevic, J., \& Bjelica, D. (2017). Body height and its estimation utilizing arm spam measurements in male adolescents from northern region in Montenegro. Acta Kinesiologica, 11 (Supp. 2), 75-80.

Sermaxhaj, S., Popovic, S., Bjelica, D., Gardasevic, J., \& Arifi, F. (2017). Effect of recuperation with static stretching in isokinetic force of young soccer players. Journal of Physical Education and Sport, 17(3), 1948-1953. doi: 10.7752/jpes.2017.03191

Vasiljevic, I., Bjelica, D., Popovic, S., \& Gardasevic, J. (2015). Analysis of nutrition of preschool-age and younger school-age boys and girls. Journal of Physical Education and Sport, 15(3), 426-428. doi:10.7752/ jpes.2015.03063

Vasiljevic, I., Bjelica, D. \& Gardasevic, J. (2018). Analysis of nutrition for boys and girls who are first cycle pupils in primary school. Sport Science, $11(1), 15-18$ 